\title{
Assessing the Political Economy Factors on Trade Integration : Rules of Origin under NAFTA
}

\author{
Alberto Portugal-Perez \\ The World Bank
}

\begin{abstract}
Rules of origin (RoO) are legitimate policy instruments to prevent trade deflection in a Preferential Trade Agreement (PTA) short of a customs union. Yet, when captured by special interest groups, RoO can restrict trade beyond what is needed to prevent trade deflection. By how much do political economy factors account for the stringency of RoO? This study quantifies the impact of both determinants, those deemed as "justifiable" on the ground of preventing trade deflection and those arising from "political economy" forces, on the restrictiveness of RoO under NAFTA. The main finding is that political economy forces, especially from the US, significantly raised the restrictiveness of the RoO. Thus stricter RoO are associated with higher production costs reducing the potential benefits of enhanced market access initially pursued by the agreement.

- JEL Classification: F13, F15, P16

- Keywords: NAFTA, Rules of Origin, Regional Integration, Political Economy.

\section{Introduction}

The increasing number of North-South Preferential Trade Agreements (PTAs), whether reciprocal (such as NAFTA) or non reciprocal (such as the Generalized System of Preferences) has generated renewed interest in market access conditions and the potential benefits reaped from this type of agreements. Rules of origin ( $\mathrm{RoO})$ are increasingly perceived as crucial issues in this context. Whether

*Corresponding address: Alberto Portugal-Perez; Development Research Group (DECRG) The World Bank 1818 H St.NW, Mailstop: MC 3-303, Washington, DC 20433. Tel: 202 473-7482, Fax: $202522-$ 1159. E-mail: aportugalperez@worldbank.org

(C)2011-Center for Economic Integration, Sejong Institution, Sejong University, All Rights Reserved.
\end{abstract}


reciprocal or not, when two or more countries sign a Preferential Trade Agreements (PTA), short of a Customs Union, they eliminate tariffs on products sold within their group while still maintaining their own varied tariff-schedules for imports from countries outside the group. They risk trade deflection: exporters may move a product into the nation with the lowest tariff, and then trans-ship it to a higher-tariff group member. Rules of origin (RoO) are then needed to prevent trade deflection.

In practice, RoO usually involve a set of complex norms and regulations that are negotiated on a product-by-product basis prior to the signature of any PTA. The process may become complex and cumbersome giving enormous scope for influence by organized interest groups from any of the partner countries in a way that suits best their interests and is not directly related to their economic justification of preventing trade deflection. As a result, RoO can curb trade beyond what is needed to this means, by creating additional costs to producers that can be even larger than their expected benefits from preferential market access, and therefore limit the potential benefits from improved market access originally intended by the PTA

A number of recent empirical contributions focused on assessing the effects of $\mathrm{RoO}$ on export costs, trade volumes and utilization rates of trade preferences, as well as on their political economy determinants. ${ }^{1}$ On the latter, Estevadeordal (2000) and Cadot et al.(2006b) estimated endogenous RoO equations for NAFTA, the free trade agreement between Mexico, Canada and the United States. By regressing an ordinal index of restrictiveness for $\mathrm{RoO}$ on a range of variables controlling for the extent of trade preferences and other variables, both studies assessed that sectors benefiting from large trade preferences also have stringent RoO. This raises the possibility that RoO may indeed reflect vested interests beyond preventing trade deflection.

This paper seeks to identify directly the contribution of political economy factors in accounting for the stringency of RoO under NAFTA. It disentangles the impact of the two types of determinants, those deemed justifiable on the grounds of preventing trade deflection, and those deemed to arise from "political economy" forces largely reflecting lobby efforts to capture any rents associated with preferences granted under NAFTA. By decomposing the determinants of RoO restrictiveness into these two groups, I estimate a hypothetical distribution of the

${ }^{1}$ See for instance: Augier et al. (2005), Cadot et al. (2005, 2007), and de Melo \& Portugal-Perez (2008). 
stringency of RoO from which the identified political economy determinants have been purged. To my knowledge, such quantification has not been attempted so far.

To anticipate, the econometric estimates in the paper show that both variables measuring the potential for trade deflection and variables measuring lobbying activities account to the restrictiveness of $\mathrm{RoO}$ which is proxied by an ordinal restrictiveness (R-index). Political economy forces, especially from the US, significantly raised the restrictiveness of RoO under NAFTA. These results imply that, by being 'unnecessarily strict' RoO raise production costs further thereby reducing the potential benefits of reciprocal market access.

The rest of the paper is organized as follows. Section II succinctly discusses the economic implications of RoO, in particular the efficiency and political economy effects associated with trade preferences and RoO. A brief description of the different types of RoO under NAFTA as well as the index summarizing their restrictiveness is provided in section III. Section IV presents the empirical methodology, and the results. Finally, section V concludes.

\section{The Economic Implications of RoO: Efficiency and Political Economy Aspects}

As implied by their name, RoO define the "rules" according to which a good is considered as "originating" from a member country of a PTA and hence qualifies to enjoy preferential market access to all members in the PTA. The rest of this section briefly discusses the economic implications of RoO, in particular the efficiency and rent effects associated with trade preferences and RoO since they motivate lobbying activities by interest groups.

Within a PTA, the economic justification of RoO is to prevent trade deflection, which is possible whenever the members' external MFN tariffs are different as there is an incentive to import a good in the PTA via the lowest-tariff country and re-export it at a profit to higher-tariff partners. ${ }^{2}$ To this effect, RoO determine whether a particular product has undergone "substantial transformation" in a country member to the PTA so it can be considered as originating from that country and benefit from preferential market access to other member countries. ${ }^{3}$

\footnotetext{
${ }^{2}$ In developing countries, $\mathrm{RoO}$ are often justified as part of an industrialization strategy aimed at developing industries with high value-added content.

${ }^{3}$ Under international law, the origin of a good is also given to the last country adding "substantial transformation" to the product.
} 
However, there is no simple and standard way to ascertain how much value should be added in the production of a good to qualify it as having undergone "substantial transformation". Indeed, the transformation that a product may undergo in a country could range from slight transformation (e.g. simple packing) to full production. $\mathrm{RoO}$ granting originating status when transformation is slight would be fully liberalizing whereas in the opposite case would be prohibitive.

Defining substantial transformation, and setting-up RoO accordingly is closely associated with political economy considerations since RoO have redistributive implications. In that sense, $\mathrm{RoO}$ can be seen to operate as "cushions" following the implementation of a PTA (or a Free Trade Area, which is a type of PTA). They reduce the losses that import-competing producers would suffer from an otherwise liberalizing Free Trade Area (FTA), while reducing rival export-oriented producers' gains from preferential market access as they face additional costs of compliance that reduce their potential gains. This cost-raising effect for exporters is higher, the stricter RoO, as first noted by Krueger (1999). However, the impact on exporters' costs is bounded. When RoO are stringent enough, so that potential costs of compliance exceed potential benefits from market access, exporters prefer not to comply with RoO and export to the partner under the MFN tariff so that the status-quo -prevailing before the FTA- is preserved. ${ }^{4}$

In the case of preferential trade agreements, compliance with $\mathrm{RoO}$ are a source of trade costs that would not occur if the product is sold domestically or without using the trade preferences granted by the agreement. Indeed, easing-up RoO would cut down exports costs creating an incentive to export diversification, where more productive firms would become exporters of new varieties under relaxed RoO, along the lines of the empirical evidence found by Demidova, Kee and Krishna (2006).

Clearly, producers from one country competing with exporters of other member countries, have an incentive to persuade their government to negotiate stricter RoO, i.e. requiring a greater degree of "transformation", since this raises the costs of their rivals, while mitigating their losses. At the other extreme, producers of exporter-

\footnotetext{
${ }^{4}$ The effects of $\mathrm{RoO}$ on the imported-good market are similar to those caused by tariffs even if they are more difficult to quantify than in the case of tariffs, due to their complexity. However, the distortion induced by RoO generate a deadweight loss that could be comparable with a governement's tariff revenue in the case of an "equivalent" tariff, assuming constant per-unit costs of compliance with RoO. Carrere and de Melo (2006) estimate econometrically an average ad-valorem equivalent of $3.2 \%$ for NAFTA's RoO by extracting information on the responsiveness of preference utilization rates on different types of RoO.
} 
oriented sectors would benefit from lenient or non-binding RoO, since they would avoid an increase in costs. Therefore, they have an incentive to get mobilized to countervail rival import-competing lobbies that profit from more stringent RoO. ${ }^{5}$

In a vertical type of trade, as in the case of many activities under NAFTA, RoO can also procure captive markets to producers upstream. It occurs when exporters of intermediate goods manage to impose RoO designed to compel downstream producers of other member countries to purchase their intermediates so that their exports fulfil the "origin" requirements and benefit from preferential market access conferred by the FTA arrangement. Northern producers of intermediates may take advantage of them and emerge as winners, since Southern producers might have chosen not to source intermediates from the Northern partner in the absence of restrictive RoO. This is called trade suppression by Rodriguez (2001). Northern partners are generally producers of the intermediate good that may be capital intensive and the Southern producers are the final good assemblers, an activity generally labor-intensive. ${ }^{6}$ Indeed, in the presence of $\mathrm{RoO}$ requiring a higher value content of inputs produced in the "zone", Southern exporters of the final good have to increase their purchases of intermediates from Northern producers, who may not have the lowest production costs.

$\mathrm{RoO}$ resulting from negotiations not only depend on the effectiveness of lobbies within each member party, but also on the relative bargaining power of governments. In the case of a North-South FTA, it has been recognized that the Northern partner typically has greater leverage than Southern members in influencing RoO. On the basis of strong evidence, some authors (such as Anson et al. (2005) and Cadot et al. (2006b)) have assumed that it is exclusively the Northern government that sets the level of restrictiveness of $\mathrm{RoO}$ in such a way that Southern producers are left on their "participation constraint". In such a case,

\footnotetext{
${ }^{5}$ To the extent that importers (or intermediaries) may have market power, a considerable part of the rents due to tariff preferences are likely to be captured by them, rather than by the exporters themselves, as found by Olarreaga and Ozden (2005) in the case of apparel exports to the US under AGOA. Then, intermediaries are encouraged to lobby for less restrictive RoO, aligning themselves with exporters from the other country, so that the latter do not face bigger costs and the volume of their exports under preferential access increases.

${ }^{6}$ Textiles and apparel are a typical case. In the production of apparel, "it is the sewing stage that has been most difficult to mechanize. Almost every other stage of apparel production has gradually replaced labour with capital, in a trend that mirrors cotton production in the US. Despite millions of dollars in research in mechanization, people are still required to piece together fabric and feed it into sewing machines." (Rivoli (2005), 68).
} 
producers stay indifferent between complying with RoO and using preferential market access, or not complying with them and exporting "preference-free" under the MFN tariff. ${ }^{7}$

RoO have an advantage over exclusions that can be incorporated in the agreement. Instead, they provide more flexibility and thus, an intermediate situation between full-liberalization and full-exclusion helping to strike a balance between conflicting interests. Indeed, while negotiating an FTA, RoO can be seen as fundamental to assure political support for the successful completion of the agreement from politically sensitive sectors. There is some anecdotic evidence on the deployment of political strength by US lobbies during NAFTA talks. Destler (2006) narrates how US Representatives from North Carolina shifted their stance from opposition to the extension of fast-track procedures (a de facto authorization for the Bush administration to pursue NAFTA negotiations), to support to it, once RoO known as "yarn-forward rules" were negotiated for textiles and apparel. These particularly ingenious rules require that the three basic processes of making a piece of apparel (the making of fibber, cloth, then clothing) take place in a NAFTA country. Since textile producers in North Carolina had a comparative advantage in textile production within the NAFTA region, they stood to gain by this policy that forced Mexican producers of apparel to buy textiles from them, instead of from other cheaper sources.

\section{RoO under NAFTA: Description and Measurement of their Restrictiveness}

Generally, there are two components: regime-wide RoO and product-specific rules of origin (PSRO). Regime-wide RoO consist essentially of cumulation and de

\footnotetext{
${ }^{7}$ This assumption is very convenient to model endogenous RoO in the case of "captive markets for intermediates" to illustrate how southern producers are confronted to a trade-off between profiting from preferential market access and using more expensive intermediates from the North to comply with RoO. However, when this assumption is applied to a more general model, two opposite corner solutions are found concerning RoO imposed by the Northern government. In the first corner solution, RoO take the strictest possible level (fully-excluding) for a good when the Northern country is importer of it and in the second one, RoO take the more lenient possible level of RoO (fully-liberalizing) when the country is exporter (assuming that there is only one type of producer in each tariff line). In reality, the restrictiveness of RoO is observed to vary widely even across products of the same sector.
} 
minimis thresholds and are described in more detail in Appendix A.1. ${ }^{8}$

PSRO determine eligibility at the tariff-line level according to two basic criteria.

Firstly, the wholly obtained or produced criterion is employed when the whole production process and all inputs used in this process should be originated from the same country in order to attribute originating status to the good. Only one country enters into consideration in attributing origin.

Secondly, the substantial transformation criterion involves two or more countries that take part in the production process. RoO define the methods by which it can be ascertained whether the good has undergone "substantial transformation" in the exported country to be granted "originating" status. It comprises three main components, which can be used in combination with each other or as stand-alone:

A. A change in tariff classification (CTC) can be expressed at various levels of aggregation in the Harmonized System (HS) nomenclature. ${ }^{9}$ From broader to narrower, origin is granted if the exported product falls into (or change) either a different chapter ( $\mathrm{CC}$ at the 2-digit level under the $\mathrm{HS}$ ); or heading ( $\mathrm{CH}$ at the fourdigit level); or subheading (CS at the six-digit level), or item (CI at the eight-digit level), than any of its imported inputs. Changes of classification expressed at broader levels of aggregation are, in principle, more constraining.

\footnotetext{
${ }^{8}$ Three types of cumulation rules are distinguished: bilateral, diagonal and full cumulation. Bilateral cumulation is most common and applies to trade between two partners in a FTA. It stipulates that producers in country A can use inputs from country B without affecting the final good's originating status provided that the inputs are themselves originating (i.e. provided that they themselves satisfy the area's ROOs). Under diagonal cumulation, countries tied by the same FTA can use materials that originate in any member country as if the materials were originating in the country where the processing is undertaken. Finally, under full cumulation, all stages of processing or transformation of a product within the FTA can be counted as qualifying content regardless of whether the processing is sufficient to confer originating status to the materials themselves. It is easy to show that full cumulation allows for greater fragmentation of the production process than the more commonly used bilateral and diagonal cumulation, and hence is less restrictive. Exploiting the change of cumulation regime in EU agreements as a natural experiment, Augier et al. (2006) find empirically that the volume of bilateral trade is lower when cumulation is on a bilateral rather than a full cumulation basis.

${ }^{9}$ The Harmonized Commodity Description and Coding System, commonly known as "HS Nomenclature", is an international multipurpose nomenclature elaborated under the auspices of the World Customs Organization. Although only 116 countries are Contracting Parties to this Convention, more than 190 administrations worldwide apply the US nomenclature, mostly to set up their national customs tariff and for the collection of economic statistical data. The HS Nomenclature comprises 20 sections further subdivided into 96 chapters (commodity group identified by 2-digit code). Chapters are subdivided into headings (4-digit codes) and subheadings (6-digit codes, about 5000 of them), where the harmonization stops. Some administrations such as Eurostat use finer classifications (up to 10 digits).
} 
The HS schedule was not designed specifically as a system used to confer origin. Indeed, in some cases it can be argued that a given level of transformation (however measured) can be identified by a change of heading for some products, whereas it cannot be identified for others. As a result, schemes using the CTC can provide a rationale for a wide range of exceptions generally prohibiting the use of non-originating materials from a certain chapter, heading, sub-heading, or item. Allowances, on the contrary, allow the use of non-originating materials from certain classifications.

B. The domestic content rule, or regional value content (VC) entails a minimum percentage of local value added in the originating country, or a maximum percentage of value originating in non-member countries.

C. Technical requirement (TECH) requires the product to undergo specific manufacturing or processing operations in the originating country or prohibits the use of certain inputs.

Appendix A3 provides examples of the definition of RoO under NAFTA, which show that product-specific rules of origin (PSRO) are complex and difficult to measure because of the combinations of criteria within and across regimes. In the case of NAFTA, the first column of Table 1 shows the number of tariff lines with positive exports for every combination of $\mathrm{RoO}$ defined under the agreement.

Estevadeordal (2000) was the first to propose a discrete RoO index based on an "observation rule" to measure the restrictiveness of the resulting complex system of PSRO. The rule was based on two assumptions. The first one, a change at the level of chapter (CC) is more restrictive than a change at the level of heading $(\mathrm{CH})$, and a change at the level of heading $(\mathrm{CH})$ is more restrictive than a change at the level of sub-heading (CS), and so on. The second assumption states that the value content criterion (VC) and the technical requirements (TECH) attached to a given change of tariff classification (CTC) add restrictiveness to the RoO. Based on this observation rule, the resulting ordinal index $\left(\mathrm{R}_{\mathrm{i}}\right)$ assigns a single value, ranking from 1 (less stringent) to 7 (more stringent), to the restrictiveness of RoO (i.e. $1 \leq$ $\left.R_{i} \leq 7\right)$. Subsequently, Cadot et al. (2006c) modify the index mainly by taking into consideration exceptions and allowances. Appendix A2 details the construction of their index (henceforth the R-index) that is used in this study.

The last column of Table 1 presents the value of the R-index assigned to all combinations of PSRO existing in NAFTA at the HS-6 level of aggregation. The histogram of the distribution of the R-index computed for the 4077 tariff lines is 
Table 1. Description of RoO under NAFTA.

\begin{tabular}{lccc}
\hline RoO criteria & \multicolumn{2}{c}{$\begin{array}{c}\text { Observations. } \\
\text { (HS-6 level) }\end{array}$} & R-indexvalue $\left(^{*}\right)$ \\
\hline $\mathrm{NC}$ & 2 & $0.05 \%$ & 1 \\
$\Delta \mathrm{I}+\mathrm{EXC}$ & 1 & $0.02 \%$ & 2 \\
$\Delta \mathrm{SH}$ & 42 & $1.03 \%$ & 2 \\
$\Delta \mathrm{SH}+\mathrm{EXC}$ & 113 & $2.77 \%$ & 3 \\
$\Delta \mathrm{SH}+\mathrm{TECH}$ & 2 & $0.05 \%$ & 3 \\
$\Delta \mathrm{SH}+\mathrm{EXC}+\mathrm{TECH}$ & 20 & $0.49 \%$ & 3 \\
$\Delta \mathrm{H}$ & 736 & $18.05 \%$ & 4 \\
$\Delta \mathrm{I}+\mathrm{EXC}+\mathrm{VC} 2$ & 1 & $0.02 \%$ & 5 \\
$\Delta \mathrm{SH}+\mathrm{EXC}+\mathrm{VC} 2$ & 4 & $0.10 \%$ & 5 \\
$\Delta \mathrm{H}+\mathrm{EXC}$ & 720 & $17.66 \%$ & 5 \\
$\Delta \mathrm{H}+\mathrm{TECH}$ & 1 & $0.02 \%$ & 5 \\
$\Delta \mathrm{H}+\mathrm{EXC}+\mathrm{TECH}$ & 2 & $0.05 \%$ & 5 \\
$\Delta \mathrm{H}+\mathrm{VC} 1$ & 21 & $0.52 \%$ & 5 \\
$\Delta \mathrm{H}+\mathrm{VC} 2$ & 140 & $3.43 \%$ & 6 \\
$\Delta \mathrm{H}+\mathrm{EXC}+\mathrm{VC} 1$ & 25 & $0.61 \%$ & 6 \\
$\Delta \mathrm{C}$ & 1188 & $29.14 \%$ & 6 \\
$\Delta \mathrm{H}+\mathrm{EXC}+\mathrm{VC} 2$ & 3 & $0.07 \%$ & 7 \\
$\Delta \mathrm{H}+\mathrm{TECH}+\mathrm{VC} 2$ & 5 & $0.12 \%$ & 7 \\
$\Delta \mathrm{C}+\mathrm{EXC}$ & 775 & $19.01 \%$ & 7 \\
$\Delta \mathrm{C}+\mathrm{TECH}$ & 1 & $0.02 \%$ & 7 \\
$\Delta \mathrm{C}+\mathrm{EXC}+\mathrm{TECH}$ & 275 & $6.75 \%$ & 7 \\
\hline Total lines & 4077 & $100 \%$ & 5 \\
\hline
\end{tabular}

Notes: $\Delta \mathrm{C}=$ Change in Chapter $/ \Delta \mathrm{H}=$ Change in Heading $/ \Delta \mathrm{SH}=$ Change in Subheading $/ \Delta \mathrm{I}=$ Change in Item / EXC $=$ Exception to Change of Tariff Classification / RC1 = Regional Value Content $<60 \%$ / $\mathrm{RC} 2=$ Regional Value Content $\geq 60 \% / \mathrm{TECH}=$ Technical Requirement.

${ }^{*}$ ) The ordinal R-index takes values $1 \leq R o O_{i} \leq 7$, with higher values corresponding to more stringent requirements.

Source: author's estimates using data in Cadot et al. (2006c)

shown as Figure 1. The bulk of the distribution is concentrated around the values of 4 and 7.

Table 1 shows that RoO under NAFTA are complex and heterogeneous across products. One can argue that the fact that HS classification was not elaborated to determine origin can bring about complex combinations of PSRO. However, RoO can be simpler as in the case of the Asian Free Trade Agreement (AFTA) where they are formulated as a single minimum regional content value of $40 \%$ for basically all products. Indeed, the fact that under some PTAs, RoO are simpler and more homogeneous across product lines, may be interpreted as evidence that the 
Figure 1. Distribution of R-index for NAFTA

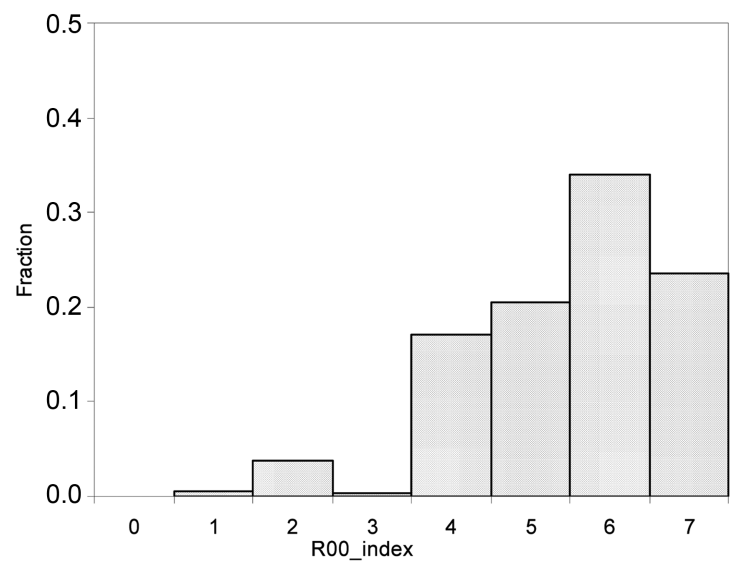

Source: author's estimates using data in Cadot et al. (2006c)

complexity of RoO facilitates capture by special interests groups by reducing the scope for free-riding resulting in greater lobbying activities. Thus, complex RoO can be "made-to-measure", i.e. tailored to the needs of the interests groups. ${ }^{10}$

\section{Estimation}

\section{A. Methodology and data}

The analysis is restricted to the interaction between Mexico and the United States, leaving Canada aside, as in previous empirical studies for NAFTA. This choice is dictated by data availability but can also be justified on several grounds. For example, many observers pointed out that the initiative to turn the initial USMexico negotiations into NAFTA came mainly from Canada, motivated by the fear of potential trade diversionary effects of a US-Mexico FTA and, thus, in order

\footnotetext{
${ }^{10}$ In addition to the inevitable arbitrariness involved in setting up the observation rule, the R-index has other shortcomings. For an elaboration of some of the shortcomings of the R-index, see e.g. Erasmus et al. (2006). In particular, the R-index is an ordinal rather than cardinal measure. To remedy these problems, one would want to build an equivalent measure of restrictiveness of the combinations of RoO in terms of a single continuous index, say for instance, a minimum local content measure. However, information on the production process of a good - detailed enough to compute such a measure- is difficult to obtain. Notice from Table 1 that there is no single product under NAFTA having a VC rule without being combined with other type of PSRO.
} 
to preserve some of the gains achieved under the pre-existing US-Canada FTA. ${ }^{11}$

Based on the above discussion, it is convenient to view RoO as determined in a two-stage procedure. In the first stage, every country $k$ (here $k=$ Mexico, US) sets a desired level of RoO $\left(\tilde{R}_{\mathrm{i}}^{\mathrm{k}}\right)$ for every good $i$ as the outcome of the interaction between industrial lobbies and the national government. ${ }^{12}$ Their resulting restrictiveness level is a function of factors generating potential trade deflection concerns $\left(T D_{i}^{k}\right)^{13}$ and also a function of political economy forces $\left(P E_{i}^{k}\right)$ internal to country $k$, i.e. $\tilde{R}_{\mathrm{i}}^{\mathrm{k}}=\mathrm{g}^{\mathrm{K}}\left(T D_{i}^{k}, P E_{i}^{k}\right)$. In the second stage, $\mathrm{RoO}$ that will finally prevail under the agreement, $\left(R o O_{i}^{*}\right)$, are established during negotiations between government representatives. For instance, one could envisage that for each tariff line, the negotiated $\mathrm{RoO}, \mathrm{RoO}_{i}^{*}$ is obtained under a Nash bargaining game in which case we could write a reduced-form expression:

$$
R o O_{i}^{*}=\mathrm{h}\left(\varpi^{U S}, \tilde{R}_{i}^{\mathrm{US}}, \varpi^{M e x}, \tilde{R}_{i}^{\mathrm{Mex}}\right)=h\left(\varpi^{U S}, P E_{i}^{\mathrm{US}}, T D_{i}^{U S}, \varpi^{M e x}, P E_{\mathrm{i}}^{\mathrm{Mex}}, T D_{\mathrm{i}}^{M e x}\right)
$$

where $\varpi^{U S}$ and $\varpi^{M e x}$ would be the US and Mexican Nash weight coefficients representing their respective bargaining power.

Taking a linear approximation to expression (1), one could then summarize the result of the bargaining process as:

$$
R o O_{i}=\beta\left[T D_{i}\right]+\gamma\left[R E_{i}\right]+\varepsilon_{i}
$$

To confront (2) to the data, I approximate the restrictiveness of the RoO by the R-index mentioned before which is defined at the HS-6 level of aggregation at which RoO were defined under NAFTA. Explanatory variables are grouped in two vectors. The first one, $T D$, contains variables controlling for the prospect of trade

\footnotetext{
${ }^{11}$ For example, Orne (2006) wrote that "Canada's bargaining weakness was most evident in the critical area of rules of origin [...]. And finally, NAFTA is about Mexico. NAFTA extends North American industrial society south into a relatively closed and much poorer economy. Canada is necessarily a bystander in this process. It never sought Mexico's inclusion in the FTA, and it was powerless to prevent it. NAFTA is ultimately bilateral, a pact between Mexico City and Washington to which Ottawa, under any government, must reluctantly subscribe".

${ }^{12}$ For instance, the framework under which the national political process formation, $\tilde{R}_{i}^{k}$, takes place can be viewed as carried out in the political support function literature (see e.g. Hillman (1989) or more recently, Grossman and Helpman (1994)).

${ }^{13}$ Local producers may be concerned about the risk of re-exporting in the partner country and will ask their government for stricter RoO to prevent it whenever the partner has a lower MFN tariff and depending on the sectoral characteristics.
} 
deflection, the problem $\mathrm{RoO}$ are supposed to prevent. Parameters of this vector are intended to capture the degree of restrictiveness that is justified on the grounds of trade deflection, i.e. the degree of restrictiveness if negotiated RoO were exclusively dedicated to this purpose. The second vector, $P E$, includes variables that serve as proxy of identified political economy forces from both countries, as will be explained later.

Including sectoral dummies, an implementable version of model (2) becomes:

$$
\begin{aligned}
R o O_{i}= & \beta_{1}\left(\tau_{i}^{U S, M e x}\right)+\beta_{3}\left(\tau_{i}^{M e x, U S}\right)+\beta_{2}\left(I_{i}^{R \text { Rach }}\right)+\gamma_{1}\left(t_{i}^{M F N, U S}\right)+\gamma_{2}\left(R C A_{i}{ }^{U S}\right) \\
& +\gamma_{3}\left(R C A_{i}^{\text {Mex }}\right)+\gamma_{4} \ln \left(X_{i}^{U S, R o W}\right)+\gamma_{5} \ln \left(X_{i}^{M e x, R o W}\right)+\sum_{j=1}^{20} \delta_{j} D_{j i}+\varepsilon_{i}
\end{aligned}
$$

where all variables are defined for tariff line i at the HS-6 level of aggregation:

- $\tau_{i}^{U S, M e x}=\operatorname{Max}\left\{0, t_{i}^{M F N, U S}-t_{i}^{M F N, M e x}\right\}$ is the difference between the 1993 US MFN tariff and the 1993 Mexican MFN tariff, when the former is higher and zero otherwise; whereas

$\tau_{i}^{M e x, U S}=\operatorname{Max}\left\{0, t_{i}^{M F N, M e x}-t_{i}^{M F N, U S}\right\}$ is the symmetric variable.

- $I_{i}^{\text {Rauch }}$ is the Rauch (1999) index of product differentiation taking three integer values. $I_{i}^{\text {Rauch }}=1,2$ and 3 for homogenous goods, reference-priced sectors, and differentiated goods, respectively;

- $t_{i}^{M F N, U S}$ is the US MFN tariff for 1993;

- $R C A I_{i}^{U S}\left(R C A I_{i}^{M e x}\right)$ is the revealed comparative advantage (RCA) index for the US (Mexico) for good i averaged out over 1991-1993, the three-year period preceding the implementation of NAFTA ${ }^{14}$;

- $X_{i}^{U S, \text { RoW }}\left(=X_{i}^{U S, \text { World }}-X_{i}^{U S, \text { Mex }}\right)$ and $X_{i}^{\text {Mex, RoW }}\left(=X_{i}^{\text {Mex,World }}-X_{i}^{\text {Mex, US }}\right)$ are US and Mexico exports to the RoW (i.e. all countries other than US or Mexico) averaged out over 1991-1993;

$-D_{j i}$ is a sectoral dummy that is equal to 1 if good $\mathrm{i}$ belongs to section $\mathrm{j}$, and zero otherwise (for $\mathrm{j}=1 \ldots 20$ ).

${ }^{14}$ Notice that: $R C A_{i}^{j}=\left(X_{i}^{j, \text { World }} / \sum_{i} X_{i}^{j, \text { World }}\right) /\left(\sum_{i} X_{i}^{j, \text { World }} / \sum_{i} \sum_{j} X_{i}^{j, \text { World }}\right)$, where $X_{i}^{j, k}$ is exports of
good i from country $\mathrm{j}$ to country (or group of countries) $\mathrm{k}$. 
Trade and tariff data was compiled from COMTRADE. I briefly describe the variables included in each vector.

\section{Trade Deflection (TD)}

What creates an opportunity for trade deflection is, above all, the fact that one of the FTA partners has a lower tariff to third parties. Therefore, $\tau_{i}^{U S, M e x}$ $=\operatorname{Max}\left\{0, t_{i}^{M F N, U S}-t_{i}^{M F N, M e x}\right\}$ is a primary indicator of the propensity to trade deflection towards the US that may happen when MFN tariffs are $h$ in the US than in Mexico. A positive and significant coefficient would be evidence that more stringent $\mathrm{RoO}$ were negotiated in tariff lines where there were greater incentives for trade deflection towards the US. As MFN tariffs were greater in Mexico than in the US for the majority of lines, it is natural to incorporate $\tau_{i}^{\text {Mex,US }}=$ $\operatorname{Max}\left\{0, t_{i}^{M F N, M e x}-t_{i}^{M F N, U S}\right\}$ in the model, which is the variable that symmetrically controls for potential trade deflection towards Mexico.

Also included in vector $T D$ is the Rauch (1999) index of differentiation $\left(I_{i}^{\text {Rauch }}\right)$ which classifies goods into three categories according to their degree of differentiation. First, "homogeneous goods" include products internationally traded in organized exchanges, with a well-defined price, such as wheat $\left(I_{i}^{\text {Rauch }}=1\right)$. Second, "reference-priced" goods include products not traded in organized exchanges, but having reference prices available in specialized publications, such as polyethylene $\left(I_{i}^{\text {Rauch }}=2\right)$. Third, "differentiated goods" do not satisfy either of the two previous criteria $\left(I_{i}^{\text {Rauch }}=3\right)$. Because of their nature, homogenous goods can be more easily subject to "trade-deflection" or "re-exporting" than differentiated goods. ${ }^{15}$ Then, the less differentiated a good, the bigger the room for trade deflection and the more justifiable restrictive $\mathrm{RoO}$ may appear to prevent this problem. The RoO equation in this paper is the first one to control for the degree of differentiation of a good.

\section{Political Economy (PE)}

The US MFN tariff for 1993, $t_{i}^{M F S, U S}$, is included to control for the extent of preferential market access to the US under NAFTA. A positive and significant coefficient would capture situations where RoO are more stringent in products for

\footnotetext{
${ }^{15}$ To clarify this point, imagine a country member to an FTA that can import a homogenous good, say sugar, and a differentiated good, say car engines, but that can also produce them locally at higher production costs. In addition suppose the country has the lowest MFN tariffs for these goods in the FTA. This fact combined with the fact that both merchandises can be stocked creates an incentive for re-exporting both goods. However, pretending that a foreign engine is locally made is more difficult vis-a-vis customs certification, than pretending that foreign sugar is locally produced.
} 
which greater market access was provided, as found in previous studies. Indeed, US industrial groups that managed to obtain higher MFN tariffs for their products prior to NAFTA were serious candidates to receive enhanced trade protection through additionally stricter RoO under NAFTA.

The revealed comparative advantage (RCA) indices for the US and Mexico $\left(R C A I_{i}^{U S}, R C A I_{i}^{M e x}\right.$ ) are proxies for industry competitiveness for each country prior to the signature of NAFTA. Notice that when the RCA index is larger than one for a given product, the percentage share of that sector in exports is larger than the world average and the country is said to have a "revealed" comparative advantage in the sector; and vice versa when the RCA index is below one. The sign of the estimated coefficients for these variables intend to capture the asymmetry in relative bargaining power and lobby effectiveness by exporters and import-competing sectors from the two countries. On one hand, larger exporters of good i prior to NAFTA may be associated with a more competitive export sector in one country that would eventually lobby for fast access to the NAFTA partner through non-binding or lenient $\mathrm{RoO}$. On the other hand, import competing sectors of the same good in the other country have interest to lobby for stricter $\mathrm{RoO}$ in order to prevent prices and profits from falling further as a consequence of accrued market access to rivals from the partner country. Many forces are at work and the net result would depend upon the relative strength of such forces. Yet, a negative sign, say for the coefficient of $R C A I_{i}^{U S}$, would indicate that US import-competing producers prevail in imposing stricter RoO over Mexican interests.

The log of US and Mexican exports to the RoW prior to NAFTA ( $X_{i}^{U S, R o W}$ and $X_{i}^{\mathrm{Mex}, \mathrm{RoW}}$ ) are taken as a proxy for the potential size of import penetration once the agreement is implemented. Indeed, the larger a country's exports of a given product to the RoW prior to potential market access granted by NAFTA, the higher the volume of goods subject to potential "rerouting" from the RoW towards the partner country once trade preferences are in place; thus, the higher the "threat" of import penetration in the importing country. Analogously, if the restrictiveness of $\mathrm{RoO}$ is positively associated with this variable for one of the partner countries, it may imply that import competing lobby groups from the other country managed to set stricter RoO in sectors where exports of the first country to the partner could increase significantly once the trade agreement is in place.

Under the assumption that the influence of US exporters' interests- and specially US importers' interests- strictly prevail over interests of their Mexican 
counterparts, the following coefficient signs are expected when estimating equation (3): $\hat{\gamma}_{1}>0, \hat{\gamma}_{2}<0, \hat{\gamma}_{3}>0, \hat{\gamma}_{4}<0$ and $\hat{\gamma}_{5}>0$.

In implementing (3), the trade-related explanatory variables are either averaged out over a three year period preceding NAFTA, as in the case of the RCA indices and the export figures, or are figures corresponding to 1993, the year previous to NAFTA implementation, as in the case of tariff data. The rationale for this choice is that industrial groups willing to influence $\mathrm{RoO}$ during negotiations assessed their gains or losses, only by taking into consideration information available until this date. Moreover, a potential source of endogeneity bias is circumvented by taking explanatory variables corresponding to a period prior to the entry into force of the trade agreement. Section dummies included in the model are assumed to control for unobserved time-invariant sector characteristics.

The paper focus solely on RoO, despite the fact that preferential tariff phase-out periods were other key instruments denying market access and subject to negotiations that could simultaneously have been determined with RoO and have analogous effects. However, those instruments have only a temporary character as opposed to RoO, which are, presumably, permanent. ${ }^{16}$ Indeed, most import tariffs disappeared before the first ten years of operation. Besides, phase-out periods are highly and significantly correlated with the R-index ${ }^{17}$ and it is safe to assume that both policies are complementary in the short run.

Since the dependent variable, the R-index, is an ordered categorical variable, the econometric specification is set-up as an ordered probit model. Then, quantitative interpretation of parameter estimates in terms of equation (3) is not possible. Therefore, in order to assess the relative importance of the two sets of determinants of RoO, I propose to estimate two "hypothetical" distributions of the R-index under two "hypothetical" scenarios or states, using the estimates of the parameters of the ordered probit model. In the first state (hereafter state A), all explanatory variables are set equal to the mean value in the regression sample (i.e. $T D_{i}=\overline{T D}$

\footnotetext{
${ }^{16}$ Although, they can in principle be subject to renegotiation in some PTAs, RoO under NAFTA have not been renegotiated to this day.

${ }^{17}$ Estevadeordal (2000) estimates a two-equation model with a two-stage procedure where the number of years to liberalization is the dependent variable in one of then and $\mathrm{RoO}$ is the dependent variable in the other one, while being also a regressor in the former equation. In this model, tariff phase-out periods are determined by RoO, but the converse is not true. The appendix of that article explains that the main econometric problem of estimating a system where the number of years to liberalization is also added as a regressor in the $\mathrm{RoO}$ equation would be the extreme complexity and non-linearity of the resulting likelihood function. Thus, he recognizes that this likelihood function would be difficult to maximize using standard methods.
} 
Table 2. Descriptive statistics

\begin{tabular}{lccc}
\hline VARIABLE & Obs & Mean & Std. Dev. \\
\hline$R o O_{i}$ & 4077 & 5.571 & 1.209 \\
$\tau_{i}^{U S, \text { Mex }}$ & 4077 & 0.003 & 0.016 \\
$\tau_{i}^{\text {Mex }, \text { US }}$ & 4077 & 0.116 & 0.115 \\
$I_{i}^{\text {Rauch }}$ & 4077 & 2.594 & 0.591 \\
$t_{i}^{\text {MFN, } U S}$ & 4077 & 0.036 & 0.053 \\
$R C A I_{i}^{U S}$ & 4077 & 0.989 & 0.869 \\
$R C A I_{i}^{\text {Mex }}$ & 4077 & 0.911 & 2.453 \\
$\ln \left(X_{i}^{\text {US, RoW }}\right)$ & 4077 & 16.286 & 2.251 \\
$\ln \left(X_{i}^{\text {Mex }, \text { RoW }}\right)$ & 4077 & 9.947 & 3.945 \\
\hline
\end{tabular}

Source: author's estimates

and $P E_{i}=\overline{P E}$ ). In the second state (hereafter state B), "political economy" factors are cancelled out by setting all variables in vector to zero $\left(P E_{i}=0\right)$ while keeping all other explanatory at their sample mean value $\left(T D_{i}=\overline{T D}\right)$. Notice that state $\mathrm{A}$ is a benchmark for state $\mathrm{B}$.

\section{B. Results}

The estimation is carried out in cross-section with 4074 observations at the HS 6 level of aggregation at which the R-index is defined. Descriptive statistics are summarized in Table 2. Some facts emerge from the data. The lower value of $\overline{\tau_{i}^{U S, M e x}}$ is due to the high number of zero-values, as Mexico had higher MFN tariffs than the US in about $90 \%$ of the tariff lines prior NAFTA. When excluding zerovalues, the average MFN tariff gap is $12.3 \%$ for products in which Mexico had higher tariffs than the US and 5.5\% when US tariffs were higher. As expected, the US had on average higher revealed comparative advantage than Mexicoacross products, as well as higher exports to the rest of the world.

As in Cadot et al. (2006b), observations are weighted by the total Mexican exports averaged out over 1990-1993 to estimate the ordered probit models. The rationale for this choice is that observations where Mexico was a larger exporter prior to NAFTA are given higher importance. This empirical choice does not change significantly the estimates, but improves the goodness of fit of the model as will be shown in robustness checks.

Table 3 reports the ordered probit estimates for three specifications. All coefficients keep the same signs across specifications. Under the assumption that 
Table 3. Regression results.

\begin{tabular}{|c|c|c|c|c|}
\hline & Specif. 1 & Specif. 2 & Specif. 3 & Specif. 3b \\
\hline & R-index & R-index & R-index & R-index \\
\hline$\tau_{i}^{U S, M e x}$ & $\begin{array}{c}8.032 \\
{[2.114]^{* * *}}\end{array}$ & $\begin{array}{c}8.133 \\
{[2.088]^{* * *}}\end{array}$ & $\begin{array}{c}8.036 \\
{[2.101]^{* * *}}\end{array}$ & $\begin{array}{c}9.428 \\
{[2.045]^{* * *}}\end{array}$ \\
\hline$\tau_{i}^{M e x, U S}$ & $\begin{array}{c}0.136 \\
{[0.425]}\end{array}$ & & & \\
\hline$I_{i}^{\text {Rauch }}$ & $\begin{array}{c}-0.393 \\
{[0.074]^{* * *}}\end{array}$ & $\begin{array}{c}-0.391 \\
{[0.073]^{* * *}}\end{array}$ & & \\
\hline$I_{i}^{\text {Rauch }=1}$ & & & $\begin{array}{c}0.489 \\
{[0.114]^{* * *}}\end{array}$ & \\
\hline$I_{i}^{\text {Rauch }=3}$ & & & $\begin{array}{c}-0.293 \\
{[0.113]^{* * *}}\end{array}$ & \\
\hline$t_{i}^{M F N, U S}$ & $\begin{array}{c}1.425 \\
{[0.873]^{*}}\end{array}$ & $\begin{array}{c}1.304 \\
{[0.785]^{*}}\end{array}$ & $\begin{array}{c}1.359 \\
{[0.787]^{*}}\end{array}$ & $\begin{array}{c}0.844 \\
{[0.781]}\end{array}$ \\
\hline$R C A I_{i}^{U S}$ & $\begin{array}{c}-0.431 \\
{[0.035]^{* * *}}\end{array}$ & $\begin{array}{c}-0.433 \\
{[0.035]^{* * *}}\end{array}$ & $\begin{array}{c}-0.434 \\
{[0.035]^{* * *}}\end{array}$ & $\begin{array}{c}-0.414 \\
{[0.038]^{* * *}}\end{array}$ \\
\hline$R C A I_{i}^{M e x}$ & $\begin{array}{c}0.015 \\
{[0.005]^{* * *}}\end{array}$ & $\begin{array}{c}0.015 \\
{[0.005]^{* * *}}\end{array}$ & $\begin{array}{c}0.015 \\
{[0.005]^{* * *}}\end{array}$ & $\begin{array}{c}0.018 \\
{[0.005]^{* * *}}\end{array}$ \\
\hline $\ln \left(X_{i}^{U S, R o W}\right)$ & $\begin{array}{c}0.077 \\
{[0.013]^{* * *}}\end{array}$ & $\begin{array}{c}0.076 \\
{[0.013]^{* * *}}\end{array}$ & $\begin{array}{c}0.075 \\
{[0.013]^{* * *}}\end{array}$ & $\begin{array}{c}0.069 \\
{[0.013]^{* * *}}\end{array}$ \\
\hline $\ln \left(X_{i}^{M e x, R o W}\right)$ & $\begin{array}{c}0.059 \\
{[0.010]^{* * *}}\end{array}$ & $\begin{array}{c}0.059 \\
{[0.010]^{* * *}}\end{array}$ & $\begin{array}{c}0.058 \\
{[0.010]^{* * *}}\end{array}$ & $\begin{array}{c}0.073 \\
{[0.009]^{* * *}}\end{array}$ \\
\hline Dcapital $_{i}$ & & & & $\begin{array}{c}0.011 \\
{[0.070]}\end{array}$ \\
\hline Dintermed $_{i}$ & & & & $\begin{array}{l}-0.059 \\
{[0.059]}\end{array}$ \\
\hline Observations & 4074 & 4074 & 4074 & 4074 \\
\hline Pseudo $\mathrm{R}^{2}$ & 0.423 & 0.423 & 0.423 & 0.423 \\
\hline
\end{tabular}

Standard errors in brackets

$*$ significant at $10 \% ;{ }^{* *}$ significant at $5 \%,{ }^{* * *}$ significant at $1 \%$

All regressions contain section dummies.

Source: author's estimates

the influence of US import-oriented and US exporter's interests prevail, most coefficients have expected signs. The only exception is the positive sign of $\gamma_{4}$ implying that lines where the US producers had a larger volume of exports to 
countries other than Mexico are associated with stricter RoO. The overall fit of the models, as summarized in the pseudo- $\mathrm{R}^{2}$ values, seems reasonable.

Column (1) of Table 3 shows results for the full specification (equation (3)). As the coefficient of $\tau_{i}^{\text {Mex, US }}$, which controls for potential trade deflection towards Mexico, is not significant, this variable is suppressed in column (2). Indeed, there is no evidence that trade deflection towards Mexico is a concern driving RoO restrictiveness. By opposition, RoO seem to be largely influenced by the US in the few lines in which there is potential room for trade deflection to the US, as illustrated by the coefficient of $\tau_{i}^{U S, M e x}$ that is significant at the $1 \%$ level across almost all specifications.

The discrete Rauch index, $I_{i}^{\text {Rauch }}$ is broken up into two dummies $\left(I_{i}^{\text {Rauch }=1}\right.$ and $I_{i}^{\text {Rauch }}{ }^{3}$ ) that are incorporated in specification (3). Indeed, $I_{i}^{\text {Rauch }=1}\left[I_{i}^{\text {Rauch }=3}\right]$ is equal to one if good $\mathrm{i}$ is homogenous [differentiated], and zero, otherwise. Again, homogeneous goods are associated with more stringent RoO, whereas differentiated goods are associated with more lenient ones. Products can be categorized as capital goods, intermediates and final goods by the the United Nations BEC classification. As an additional robustness check, Rauch variables are replaced by dummies for capital and intermediates goods. Estimates (reported in the last column of Table 3) show that there is no significant relationship between the type of good and the restrictiveness of RoO applying to it.

The parameters $(\hat{\beta}, \hat{\gamma})$ estimated from the specifications reported in Table 3 , as well as the estimated cut-offs $\left(\hat{c_{1}}\right),\left(\hat{c_{2}}\right),\left(\hat{c_{3}}\right),\left(\hat{c_{4}}\right),\left(\hat{c_{5}}\right)$, and $\left(\hat{c_{6}}\right)$ (not reported in Table 3 to save space), are used to obtain two "hypothetical" distributions of the R-index for a hypothetical good having average characteristics under state A $\left(T D_{i}=\overline{T D}\right.$ and $\left.P E_{i}=\overline{P E}\right)$ which is the benchmark, and state $\mathrm{B}\left(T D_{i}=\overline{T D}\right.$ and $P E_{i}=0$ ). As discussed before, by comparing them, the influence of political economy factors on the restrictiveness of $\mathrm{RoO}$ could be estimated in probabilistic terms.

Figure 2 shows the distributions of the R-index under the two scenarios, computed with estimated parameters of the retained specification. Since the distributions of the R-index estimated for the other specifications are similar, only the expected value of these distributions is tabulated in Table 4 for comparison purposes. Without exception, the probability of RoO taking higher values is higher under state $\mathrm{A}$ than under state $\mathrm{B}$, as reflected by a greater expected value of the estimated distribution of the R-index in the first row of Table 4, implying that political economy considerations contribute to more stringent RoO. 
Figure 2. Hypothetical distribution for specification 1.

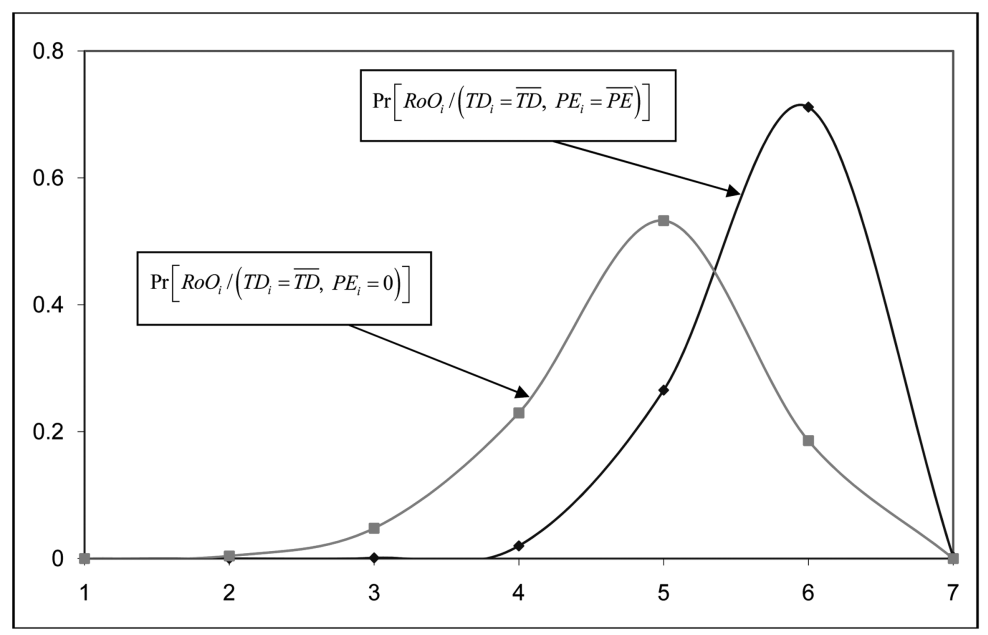

Source: author's estimates

Table 4. Estimates of the expected value of hypothetical distributions

\begin{tabular}{cccc}
\hline & Specif. 1 & Specif. 2 & Specif. 3 \\
\hline$E\left[R o O_{i} /\left(T D_{i}=\overline{T D}, P E_{i}=\overline{P E}\right)\right]$ & 5.748 & 5.748 & 5.750 \\
$E\left[R o O_{i} /\left(T D_{i}=\overline{T D}, P E_{i}=0\right)\right]$ & 4.945 & 4.941 & 4.972 \\
\hline
\end{tabular}

Source: author's estimates

Since hypothetical distributions are estimated for a hypothetical good having mean sample characteristics, section dummy variables are set equal to their sample average values under both states. Notice that by doing so, only the omission of "detected" political economy factors is considered when computing the hypothetical distribution of the R-index under state $\mathrm{B}\left(P E i=0, T D_{i}=\overline{T D}\right)$. Accordingly, even if estimates show, on average, a significant increase of the restrictiveness of RoO due to political economy forces, this increase can still be deemed as somehow conservative for at least two reasons.

First, one has to be cautious while interpreting section dummies controlling for unobserved fixed effects, since the net effect of estimated section dummy coefficients (not reported in Table 3 ) is positive and remains unchanged when estimating the two hypothetical distributions. On the one hand, from the point of view of trade deflection, section dummies capture certain unobserved technological or production characteristics that justify a differentiated degree of restrictiveness in 
RoO relative to goods from other sections. On the other hand, section dummies can capture political economy factors not explicitly identified in the vector $P E$, such as the labour intensity of the industry. Moreover, they can be interpreted as capturing an average level of restrictiveness within each section that corresponds to an average amount of required transformation that, obviously, was not captured by other regressors.

Second, there may be other forces pushing for stringent rules of origin, such as upstream industrial groups willing to capture the market of intermediate goods in the partner countries through stricter RoO, such as quantified in Cadot et al. (2004) and further discussed in Cadot et al. (2006b). If these additional factors were identified, the estimated hypothetical distribution of the R-index under state $\mathrm{B}$ $\left(P E_{i}=0, T D_{i}=\overline{T D}\right)$ would move further to the left in Figure 2. However, we do not have data available at the HS-6 level (e.g. rents, input-output coefficients, etc) to take into account potential upstream lobby capture in our estimates. Taking this data limitation into account, the hypothetical distribution can be interpreted as an upper bound of the restrictiveness of RoO when "detected" political economy factors are cancelled out.

Estimates in Table 5 are aimed to check the robustness of the retained specification (1), which is reproduced in the first column. Specification 4 uses ordinary least square estimation to check that coefficient signs are unchanged.

In specification (5) the Rauch index, $I_{i}^{\text {Rauch }}$, is replaced by another version $I_{2, i}^{\text {Rauch }}$, having a greater number of products comprised in the categories "homogenous" and "reference priced" and hence less goods categorized as "differentiated". ${ }^{18}$ Coefficients remain similar but the pseudo $\mathrm{R}^{2}$ is lower than in the retained specification. Specification (6) reports estimates from an ordered

\footnotetext{
${ }^{18}$ Rauch (1999) proposes a conservative and liberal version of the index $\left(I_{i}^{\text {Rauch }}\right.$ and $\left.I_{2, i}^{\text {Rauch }}\right)$ that are derived respectively from two classifications where the number of commodities classified as either "homogeneous" or "reference priced" are either maximized or minimized. The sample of 4077 observations at the HS -6 level are divided into three categories :
}

\begin{tabular}{|lllll|}
\hline & \multicolumn{2}{c|}{$I_{i}^{\text {Rauch }}$ (conservative) } & \multicolumn{2}{c|}{$I_{2, i}^{\text {Rauch }}$ (liberal) } \\
"homogeneous" & $I_{i}^{\text {Rauch }}=1$ & 219 obs. & $I_{2, i}^{\text {Rauch }}=1$ & 333 obs. \\
"reference priced" & $I_{i}^{\text {Rauch }}=2$ & 1219 obs. & $I_{2, i}^{\text {Rauch }}=2$ & 1259 obs. \\
"differentiated" & $I_{i}^{\text {Rauch }}=3$ & 2639 obs. & $I_{2, i}^{\text {Rauch }}=3$ & 2485 obs. \\
\hline
\end{tabular}

For both versions of the index, most of the observations are classified as "differentiated" but variation is ensured by an adequate number of observations for goods either listed as "homogeneous" and "reference priced". 
Table 5. Robustness checks

\begin{tabular}{|c|c|c|c|c|}
\hline & Specif. 1 & Specif. 4 & Specif. 5 & Specif. 6 \\
\hline & R- index & $\mathrm{R}$ - index & $\mathrm{R}$ - index & $\mathrm{R}$ - index \\
\hline$\tau_{i}^{U S, M e x}$ & $\begin{array}{c}8.133 \\
{[2.088]^{* * *}}\end{array}$ & $\begin{array}{c}2.923 \\
{[1.045]^{* * *}}\end{array}$ & $\begin{array}{c}8.918 \\
{[2.063]^{* * *}}\end{array}$ & $\begin{array}{l}-0.386 \\
{[1.475]}\end{array}$ \\
\hline$I_{i}^{\text {Rauch }}$ & $\begin{array}{c}-0.391 \\
{[0.073]^{* * *}}\end{array}$ & $\begin{array}{c}-0.047 \\
{[0.037]}\end{array}$ & & $\begin{array}{c}-0.276 \\
{[0.037]^{* * *}}\end{array}$ \\
\hline$t_{i}^{M F N, U S}$ & $\begin{array}{c}1.304 \\
{[0.785]^{*}}\end{array}$ & $\begin{array}{c}0.091 \\
{[0.414]}\end{array}$ & $\begin{array}{c}1.017 \\
{[0.780]}\end{array}$ & $\begin{array}{c}0.805 \\
{[0.485]^{*}}\end{array}$ \\
\hline$R C A I_{i}^{U S}$ & $\begin{array}{c}-0.433 \\
{[0.035]^{* * *}}\end{array}$ & $\begin{array}{c}-0.326 \\
{[0.021]^{* * *}}\end{array}$ & $\begin{array}{c}-0.428 \\
{[0.035]^{* * *}}\end{array}$ & $\begin{array}{c}-0.073 \\
{[0.024]^{* * *}}\end{array}$ \\
\hline$R C A I_{i}^{M e x}$ & $\begin{array}{c}0.015 \\
{[0.005]^{* * *}}\end{array}$ & $\begin{array}{c}0.001 \\
{[0.003]}\end{array}$ & $\begin{array}{c}0.016 \\
{[0.005]^{* * *}}\end{array}$ & $\begin{array}{c}0.013 \\
{[0.008]^{*}}\end{array}$ \\
\hline $\ln \left(X_{i}^{U S, R o W}\right)$ & $\begin{array}{c}0.076 \\
{[0.013]^{* * *}}\end{array}$ & $\begin{array}{c}0.039 \\
{[0.008]^{* * *}}\end{array}$ & $\begin{array}{c}0.074 \\
{[0.013]^{* * *}}\end{array}$ & $\begin{array}{c}0.082 \\
{[0.010]^{* * *}}\end{array}$ \\
\hline $\ln \left(X_{i}^{M e x, R o W}\right)$ & $\begin{array}{c}0.059 \\
{[0.010]^{* * *}}\end{array}$ & $\begin{array}{c}0.037 \\
{[0.006]^{* * *}}\end{array}$ & $\begin{array}{c}0.066 \\
{[0.010]^{* * *}}\end{array}$ & $\begin{array}{c}-0.015 \\
{[0.005]^{* * *}}\end{array}$ \\
\hline$I_{i}^{\text {Rauch, } L}$ & & & $\begin{array}{c}-0.209 \\
{[0.062]^{* * *}}\end{array}$ & \\
\hline Constant & & $\begin{array}{c}5.625 \\
{[0.460]^{* * *}}\end{array}$ & & \\
\hline Observations & 4074 & 4074 & 4074 & 4074 \\
\hline R-squared & & 0.67 & & \\
\hline Pseudo-R-squared & 0.423 & & 0.422 & 0.254 \\
\hline NOTES & $\begin{array}{l}\text { Original } \\
\text { specific. }\end{array}$ & OLS & $\begin{array}{c}\text { Liberal } \\
\text { Rauch index }\end{array}$ & $\begin{array}{l}\text { Unweighted } \\
\text { observations }\end{array}$ \\
\hline
\end{tabular}

Expected value of hypothetical distributions

\begin{tabular}{cccc}
\hline & Specif. 1 & Specif. 5 & Specif. 6 \\
\hline$E\left[R o O_{i} /\left(T D_{i}=\overline{T D}, P E_{i}=\overline{P E}\right)\right]$ & 5.748 & 5.740 & 5.666 \\
$E\left[R o O_{i} /\left(T D_{i}=\overline{T D}, P E_{i}=0\right)\right]$ & 4.945 & 4.913 & 4.651 \\
\hline
\end{tabular}

Standard errors in brackets

$*$ significant at $10 \% ; * *$ significant at $5 \%, * * *$ significant at $1 \%$

All regressions contain section dummies.

probit model where -unlike in previous specifications- observations are unweighted. Compared to the original specification, the coefficient of $\tau_{i}^{U S, M e x}$ is negative though not significant, whereas the coefficient of $\ln \left(X_{i}^{\mathrm{Mex}, R o W}\right)$ is negative and significant as opposed to specification (1). Here, lines where Mexican 
exports to the RoW were larger in volume were associated with stricter RoO. It can be interpreted as evidence of enhanced protection on product lines that may be judged as "threatening" for US import-competing producers. However, overall, the original specification seems to better fit the sample data as shown by a higher Pseudo-R ${ }^{2}$.

In general, the original specification is robust to different estimation methods and specifications. In addition to the breakdown of $\mathrm{PE}$ and TD factors, the negative [positive] relationship between $R C A_{i}^{U S}\left[R C A I_{i}^{\text {Mex }}\right]$ and RoO restrictiveness that seems constant across most regressions ${ }^{19}$ is another contribution of this work. This robust relationship is evidence of the asymmetric power of negotiation of both countries while setting RoO.

Measurement error or misspecification of the dependent variable is a further problem to consider when estimating discrete choice models. Abrevaya and Hausman (1999) suggest a general model in which the observed dependent variable is a stochastic function of the underlying latent one. However, it is difficult in our case to state how the misspecification takes place. Without knowing precisely how the misspecification has to be integrated in the likelihood function to be maximized, the use of this technique can lead to inconsistent estimates, as warned by the authors.

Analogous to estimates of Table 4, the last two rows of Table 5 report the estimates of the expected value of the estimated R-index under state $\mathrm{A}\left(T D_{i}=\overline{T D}, P E_{i}=\overline{P E}\right)$ and $\mathrm{B}\left(T D_{i}=\overline{T D}, P E_{i}=0\right)$ which is also higher under the former state.

\section{Conclusions}

RoO can be seen as devices used to cushion the distributive effects of an FTA on import-competing and export-oriented producers and, as such, they are subject to capture by interest groups representing these producers. Because of their complexity, their opaqueness, and the fact that they are defined at a quite disaggregated level, $\mathrm{RoO}$ can be seen as well-targeted instruments for protection since they are in effect "made-to-measure" thereby overcoming the "free-rider" problem inherent in more transparent protective devices such as tariffs. Rules of

\footnotetext{
${ }^{19}$ The only exception is the negative coefficient of $R C A I_{i}^{M e x}$ in specification 5. However, the coefficient is not significant.
} 
origin can also raise trade costs for exporters and importers - and increasingly important factor in the trading environment particularly in relation to finding ways to expand trade for developing countries.

In many ways, $\mathrm{RoO}$ are akin to traditional rent-seeking activities associated with quantitative restrictions; all in all, $\mathrm{RoO}$ are non-tariff barriers in the context of PTAs short of a customs union. This paper represents an attempt to estimate the impact of lobbying activities directed towards capturing these rents on the restrictiveness of RoO, and to estimate the costs associated with them.

Despite the caveats due to the use a synthetic index to represent the complexity inherent in the array of PSRO typical to qualify for preferences, the estimations seem plausible. The main finding is that political economy forces, especially from the US, significantly raised the restrictiveness of the RoO. The overall results confirm a strong inertia in protectionism in the US where import-competing sectors that were most protected before NAFTA obtained stricter RoO, to the detriment of Mexican exporters.

Conversely, US export-oriented industries that appear more competitive in the years preceding NAFTA were granted more lenient RoO. This can be interpreted as further evidence on the asymmetric power of negotiation in a North- South FTA. The South, in particular, stands to be damaged by RoO that can be easily manipulated to negate market-access promises made by the North in the course of negotiations. This research attempts to measure "detectable" political economy forces raising the stringency of RoO. Nevertheless, it is likely that other forces pushing for harsher $\mathrm{RoO}$ are also at play. Among the more important ones, are upstream lobbying leading to capture intermediates markets in partner countries, for which data is not available to take them into account in our estimates. From this perspective, our estimates of the stringency of RoO due to political economy forces can be seen as a lower bound.

Trade deflection plays an important role as far as the US is concerned. RoO were demanded and pushed largely by the US in lines where there was a risk for potential trade deflection to the US. Conversely, no evidence has been found that preventing trade deflection towards Mexico plays a role driving RoO restrictiveness.

Finally, while the estimates here should be considered a "first attempt" at disentangling political-economy from trade deflection motives and are very rough estimates indeed, they are coherent with the accumulating evidence that rentseeking activities by the well-organized interest-groups in the preference-granting 
country.

\section{Acknowledgments}

Without implicating them, I would like to thank Jaime de Melo for guidance as well as Olivier Cadot, Céline Carrère, Marion Jansen, Jaya Krishnakumar, Daniel Lederman, Marcelo Olarreaga, Mathias Thoenig, John S. Wilson, as well as participants of the annual meeting of Latin America and Caribbean Economic Association (LACEA), the research seminar held at the World Bank, and the Annual Conference of the European Trade Study Group in Vienna, for helpful comments on earlier versions of this paper.

Received 6 August 2010, Revised 24 January 2011, Accepted 18 February 2011

\section{References}

Abrevaya, J. and Hausman, J. A. (1999), Semiparametric Estimation with Mismeasured Dependant Variables: An Application to Duration Models for Unemployment Spells, Annales d'Économie et de Statistique, No 55-56.

Anson, José, Olivier Cadot, Antoni Estevadeordal, Akiko Suwa-Eisenmann, Jaime de Melo, and Boloorma Tumurchudur. (2005), Rules of Origin in North-South Preferential Trading Arrangements with an Application to NAFTA, Review of International Economics, 13(2), 501-17.

Augier, P., Gasiorek, M., and Lai-Tong, C. (2005), The impact of rules of origin on trade flows, Economic Policy, 20(43), July.

Brenton, P., and H. Imagawa. (2004), Rules of Origin, Trade and Customs, In J. Sokol and L. de Wulf, eds., The Customs Modernisation Handbook.Washington, D.C.:World Bank.

Cadot, Olivier, Céline Carrère, Jaime de Melo, and Alberto Portugal-Pérez. (2005), Market Access and Welfare under Free Trade Agreements: Textiles under NAFTA, World Bank Economic Review, 9(3), 415-430.

Cadot O., de Melo J. \& Portugal-Pérez A. (2007), Rules of Origin for Preferential Trading rrangements: Implications for the ASEAN Free Trade Area of EU and US Experience. Journal of Economic Integration, 22, 288-319.

Cadot, Olivier, Jaime de Melo and Marcelo Olarreaga. (2004), Lobbying, Counterlobbying, and the Structure of Protection in Rich and Poor Countries, The World Bank Economic Review, 18(3), 345-66.

Cadot, Olivier, Antoni Estevadeordal, Akiko Suwa-Eisenmann, and Thierry Verdier, eds. (2006a) The Origin of Goods: Rules of Origin in Regional Trade Agreements. 
London: Oxford University Press.

Cadot, Olivier, Antoni Estevadeordal, and Akiko Suwa-Eisenmann. (2006b), Rules of

Origin as Export Subsidies, in Cadot et al. eds., The Origin of Goods: Rules of Origin in Regional Trade Agreements. Oxford University Press

Cadot, Olivier, Céline Carrère, Jaime de Melo, and Bolormaa Tumurchudur. (2006c),

Product Specific Rules of Origin in EU and US Preferential Trading Arrangements:

An Assessment, World Trade Review, 199-225 (also CEPR DP\#4998)

Carrère, Céline, and Jaime de Melo. (2006), Are Different Rules of Origin Equally

Costly? Estimates from NAFTA, in Cadot et al. eds. The Origin of Goods: Rules of

Origin in Regional Trade Agreements.

de Melo, Jaime \& Portugal-Pérez, Alberto. (2008), Rules of Origin, Preferences and

Diversification in Apparel: African Exports to the US and to the EU, CEPR

Discussion Papers 7072, UK

Demidova, Svetlana \& Hiau Looi Kee \& Kala Krishna. (2006), Do Trade Policy Differences Induce Sorting? Theory and Evidence from Bangladeshi Apparel

Exporters, Policy Research Working Paper 3840, World Bank, Washington, DC.,

Destler. (2006), Rules of Origin and US trade policy, in Cadot et al. eds., The Origin of Goods: Rules of Origin in Regional Trade Agreements. Oxford University Press

Erasmus, H., F. Flatters, and R. Kirk. (2006), Rules of Origin as Tools of Development? Lessons from SADC, in Cadot et al. eds., The Origin of Goods: Rules of Origin in Regional Trade Agreements. Oxford University Press

Estevadeordal, A. (2000), Negotiating Preferential Access: The Case of the North American Free Trade Agreement, Journal of World Trade, 34(1), 141-66.

Estevadeordal, A. and K. Suominen. (2006), Mapping and measuring Rules of Origin around the world, in Cadot et al. eds., The Origin of Goods: Rules of Origin in Regional Trade Agreements. Oxford University Press

Grossman, Gene M. and Elhanan Helpman. (1994), Protection for Sale, American Economic Review, American Economic Association, 84(4), 833-50.

Hillman, A.L. (1989), The Political Economy of Protection, Harwood Academic Publishers, Cambridge, London

Krueger, Anne. (1999), Free Trade Agreements as Protectionist Devices: Rules of Origin, in James R. Melvin, James C. Moore, and Raymond Riezman, eds., Trade, Theory and Econometrics: Essays in Honor of John C. Chipman (New York: Routledge Press), 91-101.

Olarreaga, M., and C. Özden. (2005), AGOA and Apparel: Who Captures the Tariff Rent in the Presence of Preferential Market Access?, The World Economy, 28(1), 63-77.

Orne, W. (1996), Understanding NAFTA, Austin: University of Texas Press. ISBN 0-29276046-9

Rauch, James E. (1999), Network Versus Markets in International Trade, Journal of International Economics, 1999, 48(1), 7-35.

Rivoli, Pietra. (2005), The Travels of a T-Shirt in The Global Economy. An Economist Examines the Markets, Power, and Politics of World Trade, John Wiley \& Sons. 
ISBN 0471648493

Rodriguez, P. L. (2001), Rules of Origin with Multi-stage Production, World Economy, 24(2), 201-220.

\section{Appendix}

\section{A.1. Regime-wide Rules}

Regime-wide rules can include:

i) a de minimis (or tolerance) criterion which stipulates a maximum percentage of non-originating materials that can be used without affecting the origin of the final product.

ii) Cumulation allows FTA producers to import non-originating materials from other FTA member countries without affecting the final product's originating status. Three types of cumulation rules are distinguished: bilateral, diagonal and full cumulation. Bilateral cumulation is most common and applies to trade between two partners in a FTA. It stipulates that producers in country A can use inputs from country B without affecting the final good's originating status provided that the inputs are themselves originating (i.e. provided that they themselves satisfy the area's ROOs). Under diagonal cumulation, countries tied by the same FTA can use materials that originate in any member country as if the materials were originating in the country where the processing is undertaken. Finally, under full cumulation, all stages of processing or transformation of a product within the FTA can be counted as qualifying content regardless of whether the processing is sufficient to confer originating status to the materials themselves. It is easy to show that full cumulation allows for greater fragmentation of the production process than the more commonly used bilateral and diagonal cumulation, and hence is less restrictive.

iii) The absorption or roll-up principle allows non-originating materials which have acquired origin by meeting specific processing requirements to maintain this origin when used as input in a subsequent transformation. In other words, the nonoriginating materials are no longer taken into account in calculating value added.

iv) Duty drawbacks are refunds to exporters of tariffs paid on imported intermediate inputs. Many PTAs, especially in the Americas, mandate the elimination of duty-drawback schemes for exports to partner countries, on the ground that a duty drawback claimed by a producer in A to export to B would put that producer at a competitive advantage compared to domestic producers in $\mathrm{B}$ given that the A- 
producer already benefits from the elimination of intra-bloc tariffs. The elimination of duty drawbacks as part of a PTA's formation can imply a cut in the profitability of final-good assembly for export to partner countries in the area, although tariff escalation, when present, already provides some protection for final-assembly operations (as it implies lower tariffs on intermediate goods than on final ones).

v) Certification method. Estevadeordal and Suominen (2006) and Cadot et al. (2006c) detail the RoO for the several North-South trade agreements having either the US or the EU as the main partner.

\section{A.2. Construction of the R-index}

This annex describes the construction of the restrictiveness index (R-index) by Cadot et al. (2006b) based on the observation rule of Estevadeordal (2000). Let $D C C$ stand for a change of chapter, $D C H$ for a change of heading, $D C S$ for a change of subheading, and $D C I$ for a change of item. The index is based on the following classification convention for Change of Tariff Classification (CTC) criteria:

$$
\triangle C C>\triangle C H>\triangle C S>\triangle C I
$$

In most cases, a CTC criterion is always accompanied by one or two (in a few cases even 3) of the other requirements such as Value Content, Technical Requirement, Exception, Wholly obtained criterion, and Allowances. A value of 2 is assigned to a Change of Subheading, 4 to a Change of Heading and 6 to a Change of Chapter. Therefore the observation rule assigns higher values to the index resulting from the CTC when these other requirements are added (and assigns a lower value in the case of allowance being followed after the CTC criteria). For instance, from Table A1, a change of Heading $-\triangle C H$ takes a value of 4 , but the value increases to a 5 when $\triangle C H$ is accompanied by R1(Wholly obtained criteria) or R2(either one of $\triangle C S$, Technical Requirement and Exception). Conversely, it takes a lower value of 3 when it is accompanied by an Allowance Requirement.

In the case of a Value Content requirement, a cut-off point of $60 \%$ originating is used a value of 4 is assigned to a VC strictly smaller than $60 \%$ (VC1), and of 5 to a $\mathrm{VC}$ higher than or equal to $60 \%$ (VC2). Therefore whenever a $\mathrm{VC}$ is combined with other requirements (including a CTC) the assigned value will depend on whether the percentage of $\mathrm{VC}$ is higher or lower compared to the cut-off point of 
60\%. (See details in Table A1.)

Allowances are treated as mitigating factors that make the index jump down one level. In several cases, however, allowances are given along with certain restrictions such as adding a Value Content restriction (Allow VC). Exceptions are

Table A1. The Observation Rule to construct the R index

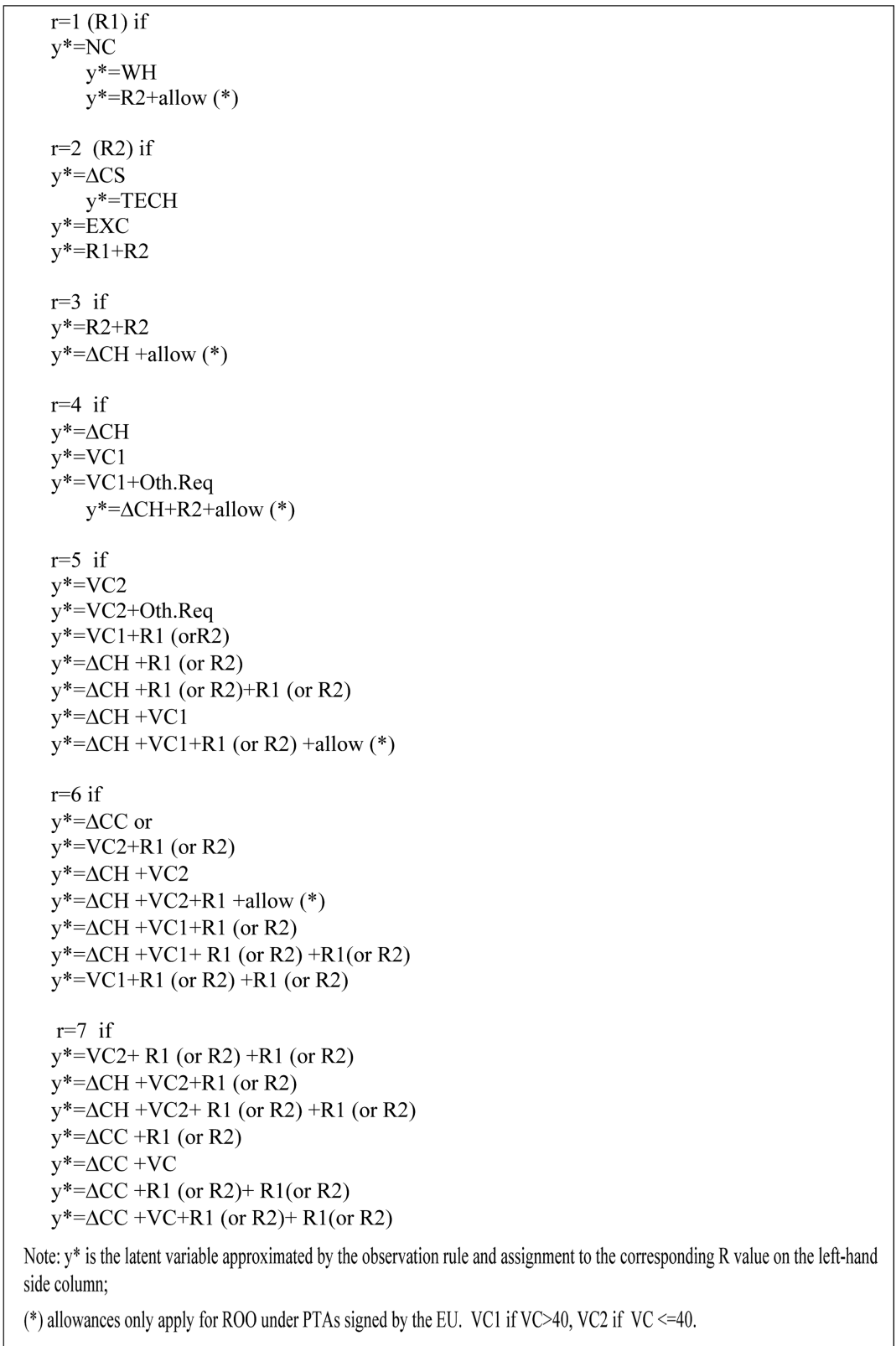

Source: Cadot et al. (2006c) 
treated as aggravating factors making the index jump up one level. Exceptions as a stand alone are assigned a value of 2 .

Table A1. lists the different combinations of RoO found by Cadot et al. for some of the US and EU preferential trade regimes and the assigned value of the R-index.

\section{A.3. Examples of Rules of Origin under NAFTA}

i) Change of tariff classification

\begin{tabular}{ll} 
HS code & Product description \\
\hline 500100 & SILKWORM COCOONS SUITABLE FOR REELING \\
500200 & RAW SILK (NOT THROWN) \\
500310 & SILK WASTE, NOT CARDED OR COMBED \\
500390 & SILK WASTE, NESOI \\
500400 & SILK YARN, NOT SPUN FROM WASTE, NOT RETAIL PACKED \\
500500 & YARN SPUN FROM SILK WASTE NOT PUT UP RETAIL SALE \\
500600 & SILK YARN \& YARN FROM WASTE RETAIL PK; SILKWM GUT \\
500710 & WOVEN FABRICS OF NOIL SILK \\
500720 & WOV FAB OV 85\% SILK OR SILK WASTE EXCEPT NOIL SLK \\
500790 & WOVEN FABRICS OF SILK OR SILK WASTE, NESOI \\
& \\
HS codes/group & Applicable Product-specific Rule of Origin (PSRO) \\
\hline $5001-5003$ & A change to heading 5001 through 5003 from any other chapter \\
$5004-5006$ & A change to heading 5004 through 5006 from any heading outside that group \\
5007 & A change to heading 50.07 from any other heading
\end{tabular}

In this example, where products are designated by their HS 6 code (sub-heading) if imported inputs are used in making silk yarn (headings 5004-5006) or silk fabric (heading 5007), those inputs must belong to different headings. Here the requirement is not overly constraining since fabric can be made with imported yarn.

ii) Exception

\begin{tabular}{ll} 
HS code & Product description \\
\hline 200911 & ORANGE JUICE, FROZEN, SWEETENED OR NOT \\
200919 & ORANGE JUICE, OTHER THAN FROZEN, SWEETENED OR NOT \\
200920 & GRAPEFUIT JUICE, SWEETENED OR NOT \\
200930 & CITRUS FRUIT JUICE FROM A SINGLE FRUIT, NESOI
\end{tabular}




\begin{tabular}{ll} 
HS codes/group & Applicable Product-specific Rule of Origin (PSRO) \\
\hline $200911-200930$ & $\begin{array}{l}\text { A change to subheading 200911 through 200930 from any other chap- } \\
\text { ter, except from heading } 0805\end{array}$ \\
HS code & Product description \\
\hline 080510 & ORANGES, FRESH \\
080520 & MANDARINS (INC TANGER ETC) \& CITRUS HYBR FR OR DRI \\
080530 & LEMONS AND LIMES, FRESH OR DRIED \\
080540 & GRAPEFRUIT, FRESH OR DRIED \\
080590 & CITRUS FRUITS, INC KUMQUATS, NESOI, FRESH OR DRIED
\end{tabular}

In this example, if imported inputs (presumably fresh oranges) are used to make orange juice (subheadings 200911 and 200919), they must belong to a different heading. That benign requirement, however, is qualified with an exception concerning heading 0805 , which covers precisely fresh oranges, grapefruit and citrus fruits.

iii) Technical requirements

HS codes/group Applicable Product-specific Rule of Origin (PSRO)

...of subheading 511111 or 511119, if hand-woven, with a loom width of ...certain textile less than $76 \mathrm{~cm}$, woven in the United Kingdom in accordance with the products rules and regulations of the Harris Tweed Association, Ltd, and so certified by the Association

Source: Brenton and Imagawa (2004) 